\title{
PAH concentrations simulated with the AURAMS-PAH chemical transport model over Canada and the USA
}

\author{
E. Galarneau ${ }^{1}$, P. A. Makar ${ }^{1}$, Q. Zheng ${ }^{1}$, J. Narayan ${ }^{1}$, J. Zhang ${ }^{1}$, M. D. Moran ${ }^{1}$, M. A. Bari ${ }^{1,2}$, S. Pathela ${ }^{1,3}$, \\ A. Chen ${ }^{1,3}$, and R. Chlumsky ${ }^{1,4}$ \\ ${ }^{1}$ Air Quality Research Division, Environment Canada, 4905 Dufferin Street, Toronto, ON, M3H 5T4, Canada \\ ${ }^{2}$ Department of Public Health Sciences, School of Public Health, University of Alberta, Edmonton, AB, T6G 2G7, Canada \\ ${ }^{3}$ Department of Computer Science, University of Waterloo, 200 University Avenue, Waterloo, ON, N2L 3G1, Canada \\ ${ }^{4}$ Department of Environmental Engineering, University of Waterloo, 200 University Avenue, Waterloo, ON, \\ N2L 3G1, Canada
}

Correspondence to: E. Galarneau (elisabeth.galarneau@ec.gc.ca)

Received: 25 April 2013 - Published in Atmos. Chem. Phys. Discuss.: 9 July 2013

Revised: 11 February 2014 - Accepted: 3 March 2014 - Published: 23 April 2014

\begin{abstract}
The offline Eulerian AURAMS (A Unified Regional Air quality Modelling System) chemical transport model was adapted to simulate airborne concentrations of seven PAHs (polycyclic aromatic hydrocarbons): phenanthrene, anthracene, fluoranthene, pyrene, benz $[a]$ anthracene, chrysene + triphenylene, and benzo[a]pyrene. The model was then run for the year 2002 with hourly output on a grid covering southern Canada and the continental USA with $42 \mathrm{~km}$ horizontal grid spacing. Model predictions were compared to $\sim 500024$ h-average PAH measurements from 45 sites, most of which were located in urban or industrial areas. Eight of the measurement sites also provided data on particle/gas partitioning which had been modelled using two alternative schemes. This is the first known regional modelling study for PAHs over a North American domain and the first modelling study at any scale to compare alternative particle/gas partitioning schemes against paired field measurements. The goal of the study was to provide output concentration maps of use to assessing human inhalation exposure to PAHs in ambient air. Annual average modelled total (gas + particle) concentrations were statistically indistinguishable from measured values for fluoranthene, pyrene and benz $[a]$ anthracene whereas the model underestimated concentrations of phenanthrene, anthracene and chrysene + triphenylene. Significance for benzo $[a]$ pyrene performance was close to the statistical threshold and depended on the particle/gas partitioning scheme employed. On a dayto-day basis, the model simulated total PAH concentrations
\end{abstract}

to the correct order of magnitude the majority of the time. The model showed seasonal differences in prediction quality for volatile species which suggests that a missing emission source such as air-surface exchange should be included in future versions. Model performance differed substantially between measurement locations and the limited available evidence suggests that the model's spatial resolution was too coarse to capture the distribution of concentrations in densely populated areas. A more detailed analysis of the factors influencing modelled particle/gas partitioning is warranted based on the findings in this study.

\section{Introduction}

Polycyclic aromatic hydrocarbons (PAHs) are ubiquitous air pollutants that tend to be most concentrated in areas of dense human population (Hafner et al., 2005) but are also detected at locations remote from local sources (Hung et al., 2005). Many PAH species have been classified as carcinogens (IARC, 2010) and they are implicated routinely as toxicants in airborne particulate matter (Kelly and Fussell, 2012). They are regulated under international agreements such as the Aarhus Protocol on Persistent Organic Pollutants. Benzo[ $a]$ pyrene, a commonly reported PAH species, is subject to ambient air guidelines in many jurisdictions.

In Canada, PAHs meet the criteria for inclusion on the toxic substances list of the Canadian Environmental 
Protection Act (Environment Canada and Health Canada, 1994), and the resulting government obligation has been to reduce or minimise their release into the environment. Nationwide anthropogenic emissions of benzo[ $[a]$ pyrene, a commonly reported species, fell by $70 \%$ between 1990 and 2010 according to estimates made by the National Pollutant Release Inventory (Environment Canada, 2012). Though there are no federal guidelines for PAHs in Canadian air, a recent analysis of ambient monitoring data found that measured PAH concentrations regularly exceed the healthbased guidelines set by the Canadian province of Ontario (Galarneau and Dann, 2011).

In the USA, PAHs are listed in the Clean Air Act as hazardous air pollutants as part of the polycyclic organic matter (POM) class of compounds (US EPA, 2012a) and have been identified as a regional cancer concern in the National-Scale Air Toxics Assessment (US EPA, 2012b). Industrial releases to air reported to the Toxics Release Inventory (TRI) fell by $35 \%$ between 1995 and 2010 (US EPA, 2012c). There is no federal US guideline for PAHs in ambient air.

PAH measurements are labour-intensive compared to those of criteria air contaminants such as ozone and particulate matter, and the processes governing their atmospheric fate are not yet well-understood. In an attempt to elucidate the spatiotemporal distributions of PAH sources and ambient concentrations, several numerical modelling studies have been published. Lagrangian frameworks have been used for Europe (Van Jaarsveld et al., 1997; Halsall et al., 2001) and China (Liu et al., 2007; Lang et al., 2007, 2008). Others studies have used box modelling (Prevedouros et al., 2004) and multimedia fate approaches (Yaffe et al., 2001; Prevedouros et al., 2008). Eulerian chemical transport models (CTMs) have been developed for Europe (Shatalov, 2005; Aulinger et al., 2007; Matthias et al., 2009; Gusev et al., 2011; Bieser et al., 2012) and east Asia (Zhang et al., 2009, 2011a, b; Inomata et al., 2012), and three such studies on a global scale have also been published in recent years (Sehili and Lammel, 2007; Lammel et al., 2009; Friedman and Selin, 2012).

The aforementioned studies differ in many respects relating to the PAH species examined, the temporal variability of their emissions, and the spatial resolutions and process representations in the models. None has focussed exclusively on North America at the regional scale. As well, although several particle/gas partitioning mechanisms have been explored in other models, including Junge-Pankow adsorption (Junge, 1977; Pankow, 1987), organic matter sorption (Finizio et al., 1997), and combined adsorption/absorption (Dachs and Eisenreich, 2000), no previous studies have evaluated model output against paired phase-distributed measurements for alternative partitioning expressions on the same domain.

This study presents the results of a chemical transport model, AURAMS (A Unified Regional Air quality Modelling System)-PAH, run over North America at $42 \mathrm{~km}$ horizontal grid spacing with hourly output for the year 2002. Seven PAH species were simulated with the model.
Three isomer pairs of decreasing volatility and increasing particulate fraction comprise six of the species: phenanthrene (PHEN) and anthracene (ANTH) $\left(178 \mathrm{~g} \mathrm{~mol}^{-1}\right)$, fluoranthene (FLRT) and pyrene (PYR) $\left(202 \mathrm{~g} \mathrm{~mol}^{-1}\right)$, and benz $[a]$ anthracene $(\mathrm{BaA})$ and chrysene/triphenylene $(\mathrm{C}+\mathrm{T})$ $\left(228 \mathrm{~g} \mathrm{~mol}^{-1}\right)$. The seventh PAH, benzo $[a]$ pyrene $(\mathrm{BaP})$ $\left(252 \mathrm{~g} \mathrm{~mol}^{-1}\right)$, is not generally considered to be semivolatile but has been included due to its common use as a representative PAH species. Two particle/gas partitioning schemes, Junge-Pankow (JP: Junge, 1977; Pankow, 1987) and DachsEisenreich (DE: Dachs and Eisenreich, 2000), were tested.

Model performance was evaluated against $\sim 5000$ measurements from 45 stations in established networks in Canada and the USA. This is the first published model to be run and evaluated for PAH concentrations and their distributions between the particle and gas phases using two partitioning methods. It is also the first such model to be evaluated over a regional North American domain.

\section{Methods}

\subsection{Model description}

AURAMS is an Eulerian CTM originally developed to simulate criteria air contaminants. The standard version of the model uses a sectional approach to represent the size distribution of airborne particles: 12 size bins from 0.01 to $40.96 \mu \mathrm{m}$ in diameter and 9 particulate species (sulphate, nitrate, ammonium, elemental carbon, primary organic aerosol, secondary organic aerosol, crustal material, sea salt, and aerosol water) are usually considered. The model includes process representation for tropospheric gas-phase oxidative chemistry, the absorptive formation of secondary organic aerosols, inorganic heterogeneous chemistry, particle microphysics (nucleation, condensation, coagulation, etc.), cloud processing of aerosols, advective transport, vertical diffusion, and gas and particle emissions and deposition. A detailed overall description of AURAMS appears in Gong et al. (2006) while a description of the aerosol sectional approach and the microphysics modules of the model can be found in Gong et al. (2003a, b). Performance evaluation and model intercomparison results for AURAMS appear in McKeen et al. (2007), Smyth et al. (2009), Makar et al. (2010), Kelly et al. (2012) and Solazzo et al. (2012) among other publications.

A modified version of the AURAMS CTM known as AURAMS-PAH was developed to incorporate primary semivolatile organic compounds that are subject to sorptive partitioning. Starting from the standard AURAMS CTM had the advantage that a number of required fields for modelling PAHs were already available. These included hydroxyl concentration, total particle surface area, and fractions of particle elemental carbon and organic carbon. The modifications made to AURAMS version 1.3.2 in order to simulate PAHs 
are described below. Physico-chemical property values used for each PAH in the modified code are found in Table S1.1 of the Supplement.

\subsubsection{Dry deposition of gases}

Within AURAMS, gaseous dry deposition velocities are modelled using the inverse resistance analogy for several land-use categories (Zhang et al., 2002). Three resistances are assessed in AURAMS and only the first of these (aerodynamic resistance) is independent of the chemical species under consideration. The species-dependent resistances are the quasi-laminar sublayer resistance and the surface or canopy resistance. The latter two depend on the gas-phase diffusivity of the compound in question, and this quantity was calculated in the model according to the Fuller et al. method described in Reid et al. (1987).

Surface or canopy resistance is the most complex of the three gaseous dry deposition component resistances and tends to dominate total dry deposition (Zhang et al., 2002). One of its subcomponents, mesophyll resistance, was set to $100 \mathrm{~s} \mathrm{~m}^{-1}$ for species that are relatively insoluble in water and have small oxidising capacities, as is the case for PAHs. The remaining subcomponents (cuticle and ground resistances) are determined by scaling to $\mathrm{O}_{3}$ and $\mathrm{SO}_{2}$ settings based on physico-chemical qualifications. For the PAHs, scaling factors to $\mathrm{O}_{3}$ and $\mathrm{SO}_{2}$ for both acetaldehyde and $\mathrm{C}_{3}$ carbonyls, the least soluble organic compounds considered in AURAMS aside from the PAHs, were used. Unsubstituted compounds such as PAHs are generally considered to have high resistances to deposition whereas carbonyl resistances are thought to be lower (Zhang et al., 2002). However, published observations of PAH deposition led us to assume that deposition velocities would be greater than zero (low resistances) and we therefore used the best-available homologues in AURAMS to represent PAHs. This is an uncertainty in the model that merits future attention.

Volatilisation of gaseous PAHs can occur from exposed water (Hoff et al., 1996), soil (Jones, 1994), and impervious urban surfaces (Diamond et al., 2000). Net gaseous deposition to the Great Lakes in 2002 was downward (Blanchard et al., 2008), suggesting that PAH fugacities in air exceeded those in surface compartments at the regional scale. Volatilisation was not included in this first-generation version of AURAMS-PAH and the effect of this omission is presented in Sect. 3.1.1.

\subsubsection{Gas-phase reactions}

Reactions of gas-phase PAHs with hydroxyl radicals are considered in this model. Since these reactions consume relatively little hydroxyl due to the trace concentrations of PAH, their reactions were simulated outside the AURAMS gasphase chemistry solver. PAH oxidative loss was estimated as a first-order process using the model-predicted $\mathrm{OH}$ concen- tration immediately preceding particle-gas partitioning. Only seven new gas-phase concentration fields were added to the CTM; PAH reaction products were not tracked in the model, either as individual gas-phase species or as contributors to SOA.

Hydroxyl reaction rate constants were taken from the program AOPWIN (atmospheric oxidation program for Microsoft Windows) which is part of the US EPA's (Environmental Protection Agency) EPI (Estimation Programs Interface) Suite (US EPA, 2006). Measured constants are available for three low-molecular-weight PAHs considered here (phenanthrene, anthracene, fluoranthene) and these values were represented in AOPWIN. However, measurements for the remaining four PAHs are not available and the software predicted the same hydroxyl reaction rate constant of $50 \times 10^{-12} \mathrm{~cm}^{3}$ molec. ${ }^{-1} \mathrm{~s}^{-1}$ for these species.

\subsubsection{Particle representation of PAHs}

Seven additional particle species, each with 12 size bins as in the original AURAMS configuration, were added to the model to represent the particle-bound PAH mass.

\subsubsection{Particle/gas partitioning of PAHs}

A new algorithm was developed for AURAMS-PAH to account for the sorptive particle/gas partitioning of PAHs. It is fully adaptable to other semivolatile species with similar atmospheric partitioning behaviour to PAHs such as dioxins and furans, PCBs (polychlorinated biphenyls), and organochlorine pesticides. The partitioning of PAHs to airborne particles was assumed to be fully reversible.

Two instantaneous equilibrium sorptive partitioning expressions were incorporated in the new partitioning subroutine. The first treated particle/gas partitioning as a Langmuirian adsorption process on a uniform particle surface (JP: Junge, 1977; Pankow, 1987). The model calculations began by adding the particulate PAH concentrations in all size bins $\left(\Sigma C_{\mathrm{p}}\right)$ and the gas-phase PAH concentration $\left(C_{\mathrm{g}}\right)$ to give a total PAH concentration $\left(C_{\mathrm{TOT}}\right)$ for each species. An updated bulk particulate fraction $(\varphi)$ was then assigned according to the first part of Eq. (1):

$\varphi=\frac{c \Sigma \theta}{c \Sigma \theta+p_{L}^{0}}=\frac{\Sigma C_{\mathrm{p}}}{C_{\mathrm{TOT}}}$,

where $c$ is a constant set at $0.173 \mathrm{~J} \mathrm{~m}^{-2}$ (estimated from Fig. 3 in Junge, 1977), $\Sigma \theta$ is the total particle surface area concentration $\left(\mathrm{m}^{2} \mathrm{~m}^{-3}\right)$ and $p_{\mathrm{L}}^{0}$ is the saturated vapour pressure of the subcooled liquid (Pa) taken from the temperaturedependent values measured by Offenberg and Baker (1999; see Table S1.1). We have selected Junge's (1977) value of $c$ over that estimated by Pankow (1987) since the latter was based on assumptions that have not been revisited in light of the numerous observations of PAH partitioning published since. The total particulate PAH concentrations dictated by $\varphi$ 
were then redistributed among the particle size bins by prorating to the proportion of total aerosol surface area concentration within each size bin. The redistributed gas-phase PAH concentration was determined by difference between $C_{\mathrm{TOT}}$ and $\Sigma C_{\mathrm{p}}$.

The second equilibrium partitioning expression available in the partitioning subroutine developed a partition coefficient $\left(K_{\mathrm{p}}, \mathrm{m}^{3} \mathrm{~g}^{-1}\right)$ based on the contributions of two additive processes: absorption into particulate organic matter and adsorption onto particulate soot (DE: Dachs and Eisenreich, 2000):

$$
\begin{aligned}
K_{\mathrm{p}} & =10^{-12}\left(1.5 f_{\mathrm{OC}} / \rho_{\mathrm{oct}} K_{\mathrm{OA}}+f_{\mathrm{EC}} K_{\mathrm{SA}}\right) \\
& =\frac{\left(\Sigma C_{\mathrm{p}} / C_{\mathrm{TSP}}\right)}{C_{\mathrm{g}}}
\end{aligned}
$$

where $\rho_{\text {oct }}$ is the bulk density of octanol $\left(0.82 \mathrm{~kg} \mathrm{~L}^{-1}\right), f_{\mathrm{OC}}$ is the organic carbon fraction of the particulate matter (the 1.5 multiplier converts organic carbon to organic matter which is assumed to be well-represented by octanol), $K_{\mathrm{OA}}$ is the octanol-air partition coefficient (dimensionless), $f_{\mathrm{EC}}$ is the elemental carbon fraction of the particulate matter, $K_{\mathrm{SA}}$ is the soot-air partition coefficient $\left(\mathrm{L} \mathrm{kg}^{-1}\right), \Sigma C_{\mathrm{p}}$ is the particulate PAH concentration across all the size bins $\left(\mathrm{ng} \mathrm{m}^{-3}\right), C_{\mathrm{TSP}}$ is the total particulate matter concentration $\left(\mu \mathrm{g} \mathrm{m}^{-3}\right)$, and $C_{\mathrm{g}}$ is the gas-phase concentration $\left(\mathrm{ng} \mathrm{m}^{-3}\right)$.

Soot-air partition coefficients $\left(K_{\mathrm{SA}} \mathrm{L} \mathrm{kg}^{-1}\right)$ were estimated as the ratios of soot-water $\left(K_{\mathrm{SW}}\right)$ to air-water partition $\left(K_{\mathrm{AW}}\right)$ coefficients since direct $K_{\mathrm{SA}}$ measurements are not available for PAHs. $K_{\mathrm{SW}}$ values from Jonker and Koelmans (2002) were used in this model. These values vary substantially (up to a factor of 47) between relevant soots for each PAH considered here. Since a single $K_{\text {SW }}$ was needed for each PAH in the model, representative values were determined by weighting the reported $K_{\mathrm{SW}}$ values by the contribution of their related combustion processes to the total emitted fine particulate matter $\left(\mathrm{PM}_{2.5}\right)$ used in the inventory of Galarneau et al. (2007). Temperature-dependent $K_{\mathrm{AW}}$ values were taken from Bamford et al. (1999). $K_{\mathrm{OA}}$ values were taken from the temperature-dependent expressions determined by Odabasi et al. (2006).

$\mathrm{PAH}$ partition coefficients were calculated according to the first part of Eq. (2). By determining the contribution of each size bin's organic matter and soot carbon to the totals across all size bins, the total particulate PAH was apportioned to each size bin. For example, if a total partition coefficient had contributions from the organic matter and soot carbon of 20 and $80 \%$, respectively, and size bin 1 held $10 \%$ of the total particulate organic matter and $15 \%$ of the total soot carbon, the fraction of total particulate PAH assigned to size bin 1 would be $14 \%$ (viz., $0.2 \times 0.1+0.8 \times 0.15$ ). Gas-phase concentrations were then determined by the difference between $C_{\text {TOT }}$ and $\Sigma C_{\mathrm{p}}$.

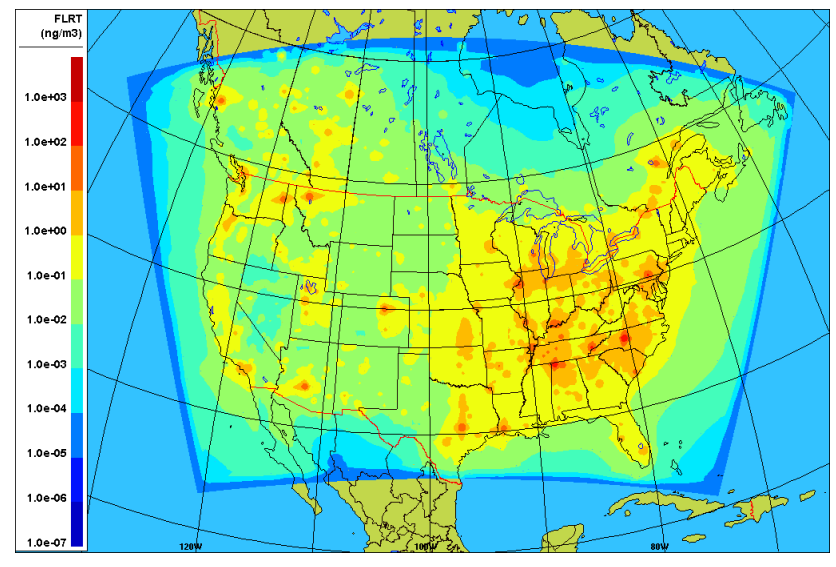

Fig. 1. Map of modelled (JP) annual average total (gas + particle) fluoranthene concentrations $\left(\mathrm{ng} \mathrm{m}^{-3}\right)$.

\subsubsection{Below-cloud (precipitation) scavenging}

Scavenging of gas and particle PAHs by liquid precipitation was calculated as per Gong et al. (2006). Particle scavenging assumed that particle-bound PAHs do not dissolve in falling rain; particle-bound PAHs were thus treated as passive aerosol tracers. Snow scavenging of gaseous PAHs was not considered in this version of AURAMS though particlebound PAHs are scavenged by snow in the model as passive components of airborne particles.

\subsubsection{Cloud processing}

Cloud processing in the model was treated in a similar manner to precipitation scavenging whereby gas-phase mass transfer to cloud water is species-dependent, whereas particulate interactions with cloud droplets are only affected by the presence of PAHs in terms of the size (mass and volume) that they represent as part of the overall aerosol. Solid-phase densities used to relate aerosol PAH mass to volume were taken from Mackay et al. (2006; see Table S1.1).

\subsection{Model domain, emissions, and boundary conditions}

The model domain included southern Canada and the continental USA (see Fig. 1). It was run on a $42 \mathrm{~km}$ polar stereographic grid using offline meteorology generated with the Global Environmental Multiscale numerical weather prediction model (GEM v 3.2.0: Côté et al., 1998a, b).

Emissions of PAHs were taken from the inventory of Galarneau et al. (2007) that had been updated from 2000 to 2002 and to which benzo[ $a$ ]pyrene had been added using identical methods and data sources. As discussed in Galarneau et al. (2007), hourly PAH emissions fields were estimated with an emissions processing system using sourcespecific temporal profiles. The temporal profile library included 3020 month-of-year, 64 day-of-week, and 2672 hourof-day temporal profiles for Canada and 1500, 49, and 680 


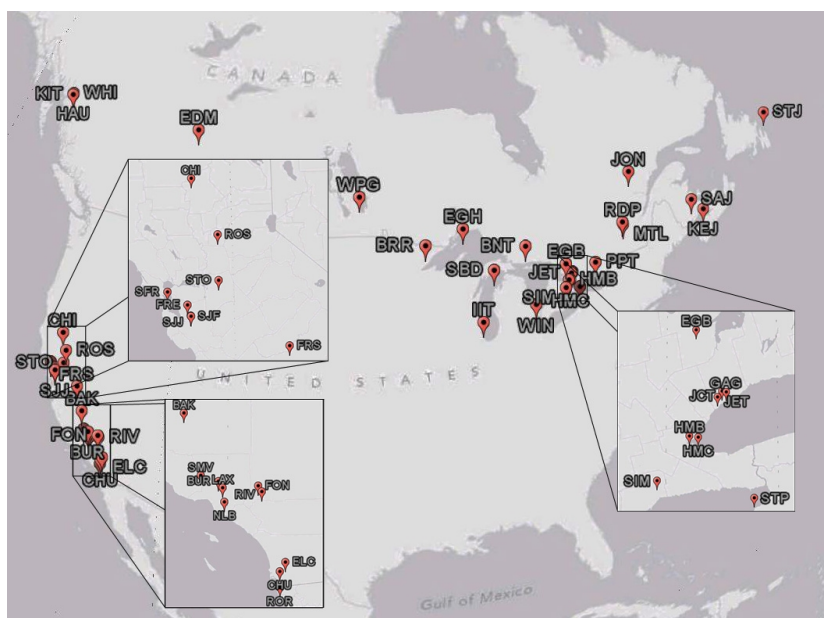

Fig. 2. Map of measurement stations used in the AURAMS-PAH evaluation.

analogous temporal profiles for the USA. The overall temporal profile thus varies from grid cell to grid cell due to the different mixtures of source types found in each one.

All PAHs were emitted exclusively in the gas phase. Particle/gas partitioning took place at each 15 min CTM time step according to the partitioning module described in Sect. 2.1.5. As mentioned in Sect. 2.1.2, no emissions of previously deposited PAHs were considered in this first-generation version of the model and the implications of this are discussed in Sect. 3.1.1. Emissions of $\mathrm{SO}_{2}, \mathrm{NO}_{\mathrm{x}}, \mathrm{NH}_{3}, \mathrm{CO}$, volatile organic compounds (VOCs), and particulate matter were derived using Environment Canada and US EPA databases and methods for the year 2002 .

Initial PAH concentrations at all lateral boundaries were set to zero in anticipation of pronounced spatial gradients away from localised source regions. As a result, modelled concentrations in Mexico and near its border with the USA are not expected to be reliable, particularly since PAH emissions from Mexico have not been included in the model. Model output along the northern edge of the domain over western Canada is similarly expected to be unreliable since emission sources are located close to the model boundary in that region. The development of representative nonzero boundary concentrations is anticipated as part of future model development.

\subsection{Evaluation data}

Observational PAH data used for comparison with model output were collected from four measurement networks: NAPS (Canada), IADN (Canada-USA), CARB (California), and Rio Tinto Alcan (Kitimat, British Columbia, Canada). The measurement stations are depicted in Fig. 2 and described in Sect. 2 of the Supplement.

Measurement data were available from a total of 45 stations, 23 in Canada and 22 in the USA, all of which col- lected samples integrated over periods of $24 \mathrm{~h}$. Particle/gas partitioning was assessed at eight stations, three in Canada and five in the USA, all of which were operated by IADN.

The IADN phase-distributed data were also combined to yield total concentrations. These combined IADN data, along with NAPS and Rio Tinto data, yielded a total of 28 sites at which the total PAH concentration for all the modelled PAHs could be assessed. Particulate PAH measurements from the latter networks were determined from samples of total suspended particles (TSP). CARB provided data for benzo[ $[a]$ pyrene in particles smaller than $2.5 \mu \mathrm{m}$ in diameter $\left(\mathrm{PM}_{2.5}\right)$ at a further 17 locations.

Four model grid squares (Kitimat, Toronto, Hamilton, and Montreal) contained two or more measurement stations thus allowing for an assessment of the adequacy of modelling all seven PAHs at $42 \mathrm{~km}$ grid spacing.

\section{Results}

\subsection{Total PAH concentration}

\subsubsection{Overall spatiotemporal domain}

Total PAH concentration refers to the sum of the gas and particulate concentrations whether these have been analysed together (e.g. NAPS) or separately (e.g. IADN). For stations at which the gas and particle phases were analysed separately, a valid total concentration was assumed to exist if at least one of the gas and particle phase concentrations was greater than the detection limit. Non-detectable values were assumed equal to zero for the calculation of total concentrations.

A representative plot of the spatial distribution of modelled annual average concentrations is presented in Fig. 1 for fluoranthene. The remaining PAHs show similar spatial distributions and maps of their modelled concentrations are found in Sect. 3 of the Supplement. All the PAHs show spatial distributions of their modelled concentrations that are consistent with regional dispersion of their emissions as depicted in Galarneau et al. (2007).

A summary of annual mean modelled and measured values over the entire spatiotemporal model domain is shown in Table 1 . Only modelled values for which there was a corresponding measurement were included.

In comparing modelled results to measurements, the annual means were statistically indistinguishable at the $95 \%$ confidence level for FLRT, PYR, BaA, and BaP (JP) whereas they were statistically different for PHEN, ANTH, C + T, and $\mathrm{BaP}(\mathrm{DE})$. For PHEN, ANTH, and C $+\mathrm{T}$, modelled values were underestimated relative to measurements whereas they were overestimated for DE BaP.

The model's temporal variability tended to be smaller than that of the corresponding measurements; the relative standard deviations of the measurements were 1.3-2.7 times greater than those of the modelled values. A similar observation has 
Table 1. Summary of the 2002 annual modelled and measured total PAH concentration mean (standard deviation) values $\left(\mathrm{ng} \mathrm{m}^{-3}\right)$.

\begin{tabular}{lrrrc}
\hline PAH & Modelled - JP & Modelled - DE & Measured & $n^{*}$ \\
\hline PHEN & $12.75(36.44)$ & $12.76(36.44)$ & $36.06(131.8)$ & 790 \\
ANTH & $0.9123(1.757)$ & $0.9104(1.759)$ & $2.804(11.56)$ & 701 \\
FLRT & $6.781(14.40)$ & $6.888(14.66)$ & $9.179(32.44)$ & 789 \\
PYR & $5.727(12.23)$ & $6.009(13.40)$ & $5.733(21.57)$ & 785 \\
$\mathrm{BaA}$ & $1.227(2.438)$ & $1.328(2.704)$ & $1.326(6.081)$ & 610 \\
$\mathrm{C}+\mathrm{T}$ & $1.511(3.964)$ & $1.473(3.569)$ & $3.303(21.95)$ & 721 \\
$\mathrm{BaP}$ & $1.173(2.002)$ & $1.424(2.455)$ & $0.9047(3.238)$ & 595 \\
${ }^{*} n=$ number of modelled-measured data pairs. & &
\end{tabular}

been made in the modelling of particulate matter with $\mathrm{AU}$ RAMS and other regional air-quality models (Solazzo et al., 2012) For PAHs, this effect was also seen by Matthias et al. (2009), who concluded that temporal variability in PAH emissions was not adequately represented by their inventory. This is a plausible contributing factor in the current study as well. Furthermore, meteorological parameters vary over a scale much finer than that used for regional air quality models. As a result, observed concentrations from point locations can be expected to exhibit greater variability than modelled concentrations determined for entire grid squares.

Differences in mean modelled total concentrations between the two partitioning versions (JP and DE) were statistically indistinguishable at a $95 \%$ significance despite the finding that the two BaP model results differed in their comparison to measured values. The latter anomaly indicates that the $\mathrm{BaP}$ distributions were close to the $95 \%$ confidence threshold. As a result, no conclusion can be drawn about which partitioning mechanism was superior in simulating overall total PAH concentrations. Phase partitioning of semivolatile organic compounds (SVOCs) is a major determinant of their potential for long-range transport (Bidleman, 1988), yet it does not appear to have a large effect on the simulation of their total concentrations at the regional scale. Model performance in simulating phase partitioning is discussed in Sect. 3.2.

The model's performance was also more closely evaluated by examining the pertinent data distributions. Figure 3 depicts frequency distributions of the ratios of modelled-tomeasured concentrations for all of the valid data pairs available for the model evaluation. Four PAH species (ANTH, FLRT, PYR, and $\mathrm{C}+\mathrm{T}$ ) yielded median values of the modelled-to-measured concentration ratio that were close to the ideal value of unity $(1.1,1.1,1.5$, and 1.4 , respectively). PHEN showed an overall tendency toward underestimation by the model (0.2), whereas $\mathrm{BaA}$ and $\mathrm{BaP}$ tended toward overestimation (3.2/3.5 and 3.0/3.5 JP/DE, respectively).

$\mathrm{BaA}$ and $\mathrm{BaP}$ are reactive PAHs (e.g. Behymer and Hites, 1985; Pöschl et al., 2001; Kwamena et al., 2004; Esteve et al., 2006, Shiraiwa et al., 2009) and the exclusion of particlebound reactions in this first-generation model may explain a portion of their overestimation in AURAMS-PAH as sug-

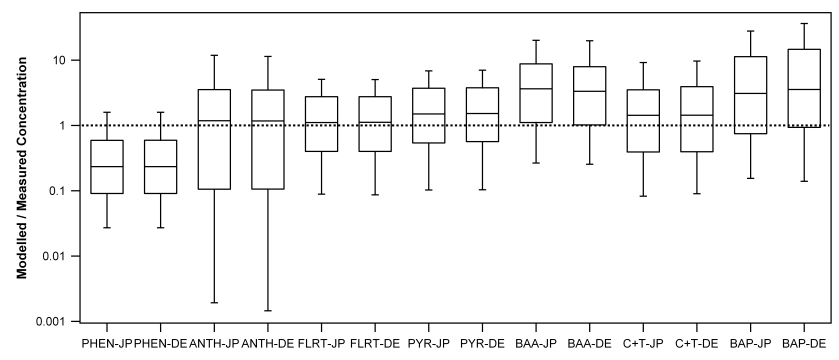

Fig. 3. All-site ensemble of modelled-to-measured concentration ratios for total (gas + particle) PAHs using JP and DE partitioning expressions. Box boundaries are 25th, 50th and 75th percentile values; whiskers are 10th and 90th percentile values. JP - JungePankow partitioning; DE - Dachs-Eisenreich partitioning.

gested in a comparable model for Europe (Matthias et al., 2009). However, $\mathrm{BaP}$ is subject to losses during sampling (Menichini, 2009) and some portion of the apparent model overestimation may in fact be due to measured concentrations that are biased low since the samplers used were not equipped with oxidant denuders. This presents a priority for future research since many jurisdictions use $\mathrm{BaP}$ as an indicator PAH when setting air quality standards.

As presented in Sect. 2.1.2, volatilisation of gaseous PAHs from surface compartments such as water and soil was not included in this first-generation version of AURAMS-PAH. If such volatilisation were significant to the balance of PAHs in ambient air relative to the other processes simulated, one would expect an overall bias in model results whereby the most volatile PAHs, which are found predominantly in the gas phase, would be underestimated and the least volatile particulate species would be unaffected. Summary results provide indefinite evidence. Volatile PHEN is systematically underestimated yet its similarly volatile isomer, ANTH, shows an ambiguous central tendency whereby its mean concentrations are underestimated by the model (Table 1) but its median concentrations are not (Fig. 3). Less volatile but nonetheless predominantly gaseous FLRT and PYR show no tendency toward underestimation.

Though results are equivocal on an annual basis, monthly patterns observed in the model output are consistent with the absence of a seasonal source (e.g. air-surface exchange). Volatilisation from a variety of environmental compartments is typically stronger in warmer periods than in cooler ones (e.g. Nelson et al., 1998; Smith et al., 2001; Motelay-Massei et al., 2005; Bozlaker et al., 2008; Wang et al., 2011). Figure 4 shows the monthly distribution of modelled-tomeasured concentration ratios for PHEN and PYR. Both exhibit higher values in winter than in summer as do ANTH and FLRT whereas this seasonality is not observed for the higher molecular $\mathrm{BaA}, \mathrm{C}+\mathrm{T}$ or $\mathrm{BaP}$ (not shown). These findings are consistent with a missing volatilisation source that emits during warmer weather. However, other factors could also be involved including overestimated loss terms 


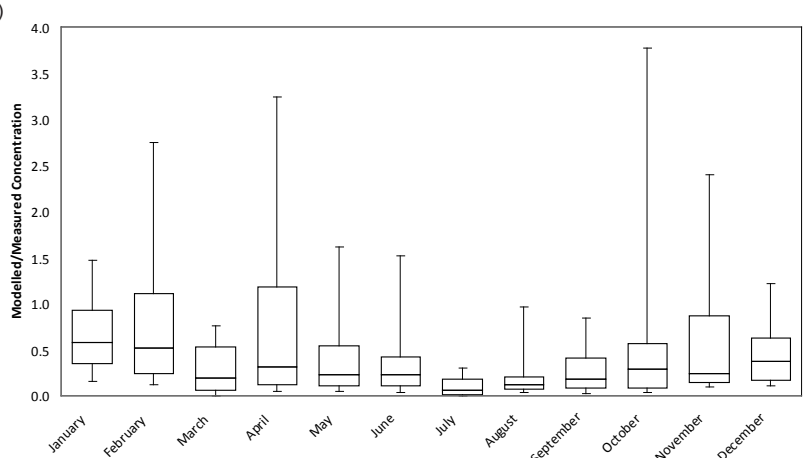

b)

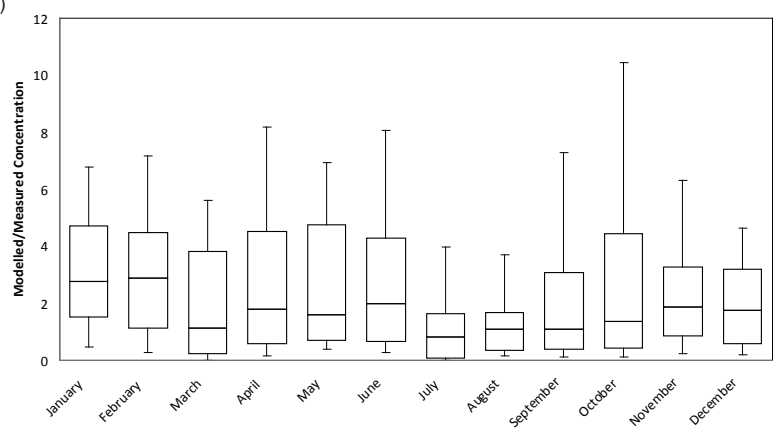

Fig. 4. All-site ensemble of modelled-to-measured concentration ratios for total (gas + particle) PHEN (a) and PYR (b) using the JP partitioning expression plotted by month.

(e.g. oxidation, deposition) or underestimated emissions (e.g. forest fires) during warmer periods. The investigation of the relevant causes is a priority for future model development. Regardless of the causes, the seasonal effect on model output appears to be compounded by further, as yet unidentified factors whereby PHEN is underpredicted throughout the year and ANTH, FLRT and PYR are overpredicted through some seasons, potentially due to air-surface exchange that leads to net deposition during cooler months.

The range of modelled-to-measured concentration ratios shown in Fig. 3 varied substantially by species. The ratios of 90th to 10th percentile values for PHEN, FLRT, PYR, $\mathrm{BaA}$, and $\mathrm{C}+\mathrm{T}$ spanned fewer than, or close to, two orders of magnitude $(55,59,67 / 68,67 / 63$, and 100/93, respectively). The ratio for $\mathrm{BaP}$ was larger $(180 / 270)$ and that for ANTH was very large (5900/7400), with extreme values tending toward underestimation for the latter species. As seen with the comparison of means, the two partitioning parametrisations used by AURAMS-PAH led to similar model performance overall when considering the distribution of total PAH concentrations.

Additional quantitative performance metrics are presented for the two particle/gas partitioning parametrisations in Tables S4.1 and S4.2 of the Supplement. The normalised mean bias and error have been included for completeness, but their utility in this evaluation is questionable given the large range of concentrations. Measured maximum to min-

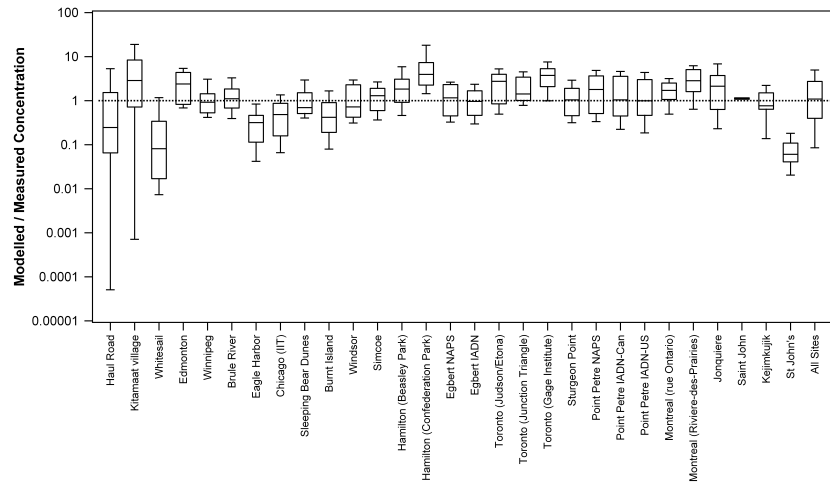

Fig. 5. Site-specific modelled-to-measured concentration ratios for total (gas + particle) fluoranthene for JP partitioning. N.B. Box boundaries are 25 th, 50th and 75th percentile values; whiskers are 10 th and 90th percentile values.

imum concentration ratios range from $4.7 \times 10^{6}(\mathrm{PYR})$ to $1.3 \times 10^{9} / 1.4 \times 10^{9}(\mathrm{C}+\mathrm{T})$. Therefore, the mean measured concentrations used to normalise the bias and error do not represent the data set well.

The correspondence between individual modelledmeasured data pairs is weak as demonstrated by the low coefficients of determination, non-unity slopes, and high intercepts listed in Tables S4.1 and S4.2 of the Supplement. However, the ability of the model to simulate observed concentrations within a certain tolerance is reasonable, especially when considering that PAHs are trace organic compounds subject to numerous sampling artefacts (McDow, 1999) and poor measurement precision (Galarneau, 2008). Depending on PAH species, 22-34\% of modelledmeasured data pairs fell within a factor of 2 of each other. This increased to $61-86 \%$ when considering a factor of 10 . As a result, it can be stated with confidence that, on average, AURAMS-PAH was able to simulate atmospheric PAH concentrations in North America for rural to urban locations to the correct order of magnitude.

\subsubsection{Site-specific performance}

Model performance was not spatially uniform. Figure 5 depicts the variation in distributions of individual modelledto-measured concentration ratios across measurement sites for fluoranthene, the PAH species for which overall performance was best as determined by the median and spread in modelled-to-measured concentration ratios. Note that only JP partitioning values have been plotted since these are visually indistinguishable from those for DE partitioning.

Of the 30 sites depicted in Fig. 5 (CARB sites could not be considered since only benzo[ $a]$ pyrene was reported there), the median modelled-to-measured concentration ratio ranged from 0.061 (St. John's) to 4.0 (Hamilton - Confederation Park), whereas the median value for all sites was 1.1. The variability at individual sites is itself highly variable, with 
Table 2. Average coefficient of variation (\%) between contemporaneous measurements at sites falling within the same $42 \mathrm{~km}$ AURAMS-PAH grid square.

\begin{tabular}{lrrrrrrrrr}
\hline Station & PHEN & ANTH & FLRT & PYR & BaA & C + T & BaP & $\mathrm{O}_{3}^{2}$ & TSP \\
\hline Kitimat & 106 & 101 & 96.5 & 93.7 & 87.4 & 91.3 & 93.2 & N/A & N/A \\
Hamilton & 52.1 & 59.0 & 59.2 & 58.8 & 73.1 & 117 & 62.8 & 24.9 & 30.5 \\
Toronto3 $^{1}$ & 36.2 & 48.7 & 42.5 & 39.6 & 42.2 & 32.9 & 43.0 & N/A & 22.1 \\
Toronto2 $^{1}$ & 36.5 & 45.4 & 39.3 & 35.7 & 32.9 & 25.0 & 38.0 & 12.2 & 24.6 \\
Montréal $^{4}$ & 49.2 & 52.9 & 45.8 & 44.6 & 55.2 & 55.3 & 51.6 & 35.3 & 29.0 \\
\hline
\end{tabular}

${ }^{1}$ Toronto3 includes data from all three Toronto measurement sites. Toronto2 includes only data from the Gage

Institute and Judson \& Etona because $\mathrm{O}_{3}$ data were not available from Junction Triangle.

2 Ozone data have been aggregated to $24 \mathrm{~h}$ concentrations contemporaneous with PAH measurements.

ratios of 90th to 10th percentile values of the modelled-tomeasured concentration ratio ranging from 5.8 (Toronto Junction Triangle) to 105000 (Haul Road, near the Rio Tinto Alcan smelter in Kitimat, British Columbia). A low value of 1.1 was observed for Saint John, but this was based on only two modelled-measured data pairs. Sixteen of the 30 sites $(53 \%)$ had median modelled-to-measured ratios that fell within a factor of two of the median value for all sites.

The other compounds varied spatially in a manner similar to fluoranthene with the following exceptions. ANTH exhibited atypically large underestimation at the three sites near the Rio Tinto Alcan smelter in Kitimat, suggesting that inaccurately low ANTH emissions are associated with the dominant source there. The reporting threshold for point-source ANTH emissions through the Canadian National Pollutant Release Inventory (NPRI) system is higher than the thresholds for other commonly measured PAHs and no ANTH emissions were reported to the NPRI by Rio Tinto Alcan for 2002. The $\mathrm{C}+\mathrm{T}$ performance at Jonquière, home to aluminum smelting facilities, suggests that reported emissions there are also too low. Emissions for other PAHs were reported from this location for 2002 but not so for chrysene, which is called benzo $[a]$ phenanthrene in the NPRI.

\subsubsection{Model grid squares containing multiple measurement sites}

The smoother the spatial distribution of a pollutant, the coarser the model resolution that can be used to simulate it. Four AURAMS-PAH model grid squares contain more than one measurement site, thus allowing for an assessment of the $42 \mathrm{~km}$ spatial resolution used for the evaluation runs. The multisite grid squares are all located in Canada, and from west to east, they encompass sites in Kitimat (2 sites), Hamilton (2), Toronto (3), and Montreal (2) (see Tables S2.1 and S2.4 in the Supplement).

Kitimat is a town $650 \mathrm{~km}$ northwest of Vancouver with approximately 9000 residents whose largest employer is the aluminum smelter complex operated by Rio Tinto Alcan (District of Kitimat, 2009). Two measurement sites (Haul Road and Kitamaat Village) are located in the same model grid square and a third site (Whitesail) lies in an adjacent square even though it is only a few kilometres away. Hamilton is a city at the western end of Lake Ontario that is known colloquially as the "Steel Capital of Canada" and had a population of approximately 700000 in 2010. It is part of the socalled "Golden Horseshoe" conurbation at the western end of Lake Ontario whose 2010 population, estimated as the sum of the populations of Oshawa, Toronto, Hamilton, and St. Catharines - Niagara, was over 7 million (Statistics Canada, 2011). Toronto and Montreal are the largest cities in Canada having 2010 populations of 5.7 and 3.9 million, respectively.

Table 2 lists the variability in contemporaneously measured concentrations at the four grid squares as represented by their coefficients of variation (COV). At any given site, the average COVs for the different PAH species tend to be similar to each other. Substantial differences exist between sites, however, particularly when grouping the urban sites (Hamilton, Toronto, and Montréal) against the industrial site at Kitimat. This is not unexpected. Urban areas include complex mixtures of point, area, and mobile sources that are distributed over distances similar to the scale of the model. Kitimat houses industrial operations within a relatively small area of otherwise rural land and wilderness. Steep spatial gradients in pollutant concentrations are expected there as a result.

The COVs for ozone and total suspended particles (TSP) have also been included in Table 2 as comparative gaseous and particulate pollutants, respectively. Both vary less between sites in the same grid square than do PAHs. Ozone and a portion of TSP are secondary pollutants created by the mixing and reaction of precursor compounds. The atmospheric residence times required for their creation is consistent with a smoothing of the spatial variability in their concentrations though ozone variability is further complicated by reactions with $\mathrm{NO}_{\mathrm{x}}$ near emissions from mobile sources. Conversely, unsubstituted PAHs are primary pollutants whose concentrations would be expected to vary in space over a finer resolution when multiple sources are found close by.

The results presented above suggest that a $42 \mathrm{~km}$ spatial resolution is not sufficiently fine to represent PAH concentrations in areas close to sources such as cities and industrial 


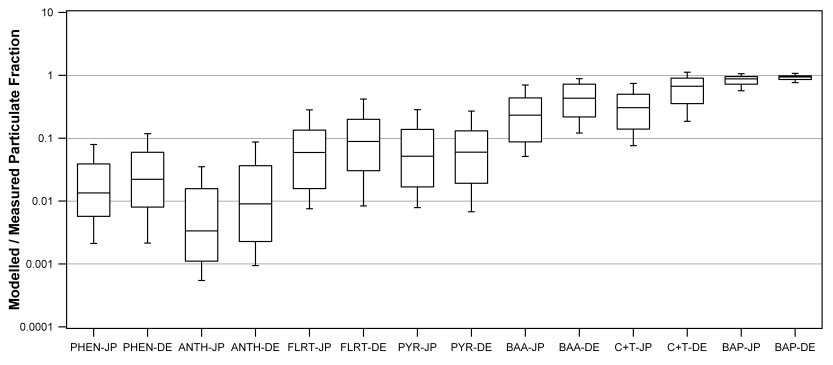

Fig. 6. All-site ensemble of modelled-to-measured PAH particulate fraction ratios for JP and DE partitioning expressions. N.B. Box boundaries are 25 th, 50th and 75th percentile values; whiskers are 10th and 90th percentile values.

areas if an average model accuracy better than an order of magnitude is desired. AURAMS modelling of fine particulate matter has shown substantial improvement when grid spacing has been reduced to $2.5 \mathrm{~km}$ (Stroud et al., 2011), and similar results can be expected for the modelling of PAHs. No $42 \mathrm{~km}$ model grid squares in rural or background areas away from sources contain multiple measurement stations and, as a result, a comparison cannot be made for these areas. However, it is expected that spatial variation in PAH concentrations will be less in such areas and, as such, a $42 \mathrm{~km}$ resolution model may be sufficient there.

\subsection{Particle/gas partitioning}

As noted in Sect. 3.1, the choice of partitioning expression (JP or DE) had little effect on the simulation of total PAH concentrations. This implies that the partitioning from each approach is sufficiently similar that regional-scale differences in removal rates between gaseous and particulate PAHs have little effect. However, differences between the two expressions with respect to simulating phase-resolved concentrations were noted.

\subsubsection{Overall spatiotemporal domain}

Figure 6 shows frequency distributions of the ratios of individual modelled-to-measured particulate fractions for all data pairs available to the model evaluation. Note that only the eight IADN stations are included since the gas and particle phases are analysed separately only at those sites.

Figure 6 shows that PAH particulate fraction is underestimated for all species except BaP. The degree of underestimation decreases with increasing molecular weight. The particulate fractions of volatile PHEN and ANTH $\left(178 \mathrm{~g} \mathrm{~mol}^{-1}\right)$ are underestimated by approximately two orders of magnitude whereas equipartitioning $\mathrm{BaA}$ and $\mathrm{C}+\mathrm{T}\left(228 \mathrm{~g} \mathrm{~mol}^{-1}\right)$ have particulate fractions that are underestimated by only a factor of two. A similar pattern appears when examining the partition coefficient, $K_{\mathrm{p}}$ (not shown).

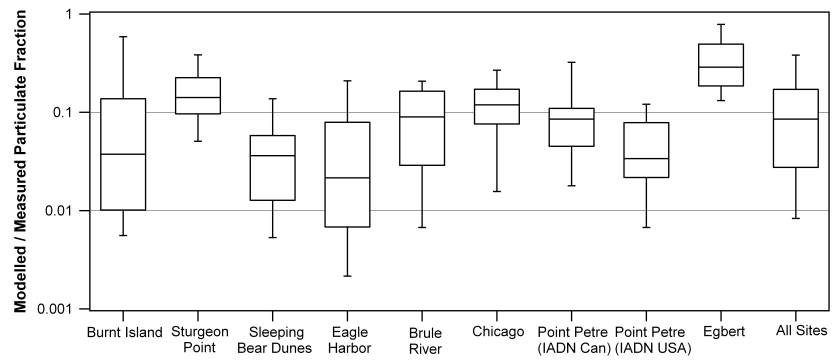

Fig. 7. Site-specific modelled-to-measured partition coefficients for fluoranthene for DE partitioning for eight IADN sites. N.B. Box boundaries are 25th, 50th and 75th percentile values; whiskers are 10 th and 90th percentile values.

For all species other than $\mathrm{BaP}$, Dachs-Eisenreich partitioning performs slightly better than Junge-Pankow partitioning in simulating measured particulate fractions. The allsite median particulate fraction simulated using DE is between 1.1 (PYR) and 2.9 (ANTH) times higher than that using JP. However, the performance of the partitioning expressions is highly dependent on the physico-chemical property values used. For example, estimated soot-air partition coefficients vary by more than an order of magnitude (Galarneau et al., 2006) and translate directly to variations in predicted partitioning by the Dachs-Eisenreich expression. For JungePankow partitioning, the value of the constant, $c$, in Eq. (1) and the estimation of aerosol surface area also introduce uncertainties. A full analysis of the sensitivity of modelled partitioning is beyond the scope of this paper and is explored in a separate publication (Galarneau, 2014).

\subsubsection{Site-specific performance}

As was the case for total concentration, there is substantial variability in the simulation of partitioning between sites. Figure 7 shows the variation in frequency distribution of individual modelled-to-measured particulate fractions for fluoranthene using Dachs-Eisenreich partitioning. Model performance for particulate fraction simulation is better at urban (Chicago) or urban-influenced (Sturgeon Point, Egbert) sites than at those that are remote (Eagle Harbor). An analysis of measured partitioning at IADN stations (Galarneau et al., 2006) found that the proportionality between partitioning and volatility varied between sites, and in some cases, over the annual cycle. Volatility is included in both the JP (through $p_{\mathrm{L}}^{0}$ ) and $\mathrm{DE}$ (through $K_{\mathrm{OA}}$ and $K_{\mathrm{SA}}$ ) partitioning expressions and the proportionality between it and partitioning magnitude is much smaller in model outputs than in measurements. As noted earlier, factors involved in the performance of model partitioning such as modelled particulate matter concentration and composition are explored in a separate publication (Galarneau, 2014). 


\section{Conclusions}

This study described the first-known modelling results for atmospheric PAHs at the regional scale over North America. Predictions from the AURAMS-PAH model were compared to roughly $500024 \mathrm{~h}$-average PAH measurements from 45 sites, eight of which also provided data on particle/gas partitioning which had been modelled using two different partitioning schemes.

The evaluation of the model is key to determining its potential utility as an input for estimating the impacts of PAH inhalation exposure on human health. Annual average modelled total (gas + particle) concentrations were statistically indistinguishable from measured values for fluoranthene, pyrene and benz $[a]$ anthracene, indicating the model's potential utility for providing inputs to health impact estimation for these species. The model's annual average concentrations for phenanthrene, anthracene and chrysene + triphenylene were biased low. For these species, the negative bias would have to be considered if used as inputs to human health impact estimates as the model in its present form underestimates long-term exposure.

The utility of the model for prediction purposes may also be considered on a day-to-day basis though this is less relevant to the chronic health effects associated with carcinogenic PAHs. The model simulated total PAH concentrations to the correct order of magnitude $64-86 \%$ of the time. That level of accuracy must be considered when assessing human health impacts; annual exposure estimates are likely of more utility with the model in its current state.

The partitioning approach chosen did not have a significant impact on the model results for total concentrations though differences resulting form the choice of parametrisation approached the $95 \%$ significance level for benzo $[a]$ pyrene. At this time, neither of the two approaches used here provided a clear advantage for simulation accuracy of total concentrations.

As a first work of this nature, the analysis has suggested several avenues for further model development and improvement. Improved temporal emission estimates for PAHs are key to improving model simulations of these species; simulated PAHs showed less temporal variability than the measurements. The reactions of particulate PAH species with atmospheric oxidants should be given further consideration since the more reactive species were overestimated in the current model. The addition of an air-surface exchange parametrisation should be evaluated as a potential response to the seasonally varying prediction capability of the model for the most volatile compounds. Model resolution has been shown to be a key factor in improving air-pollution estimates in areas with high human exposures. While the $42 \mathrm{~km}$ horizontal grid spacing used in this study is finer than that used in global models, it was insufficient to capture the distribution of concentrations in densely populated areas. A more detailed analysis of the factors influencing modelled parti- cle/gas partitioning is needed to improve the distribution of PAHs between the gas and particle phases in the atmosphere given that both partitioning schemes used here showed increasing negative biases for particle-bound PAH concentrations of increasing volatility.

\section{Supplementary material related to this article is available online at http://www.atmos-chem-phys.net/14/ 4065/2014/acp-14-4065-2014-supplement.pdf.}

Acknowledgements. The authors would like to acknowledge the contributions of the AURAMS team at Environment Canada, in particular B. Pabla, C. Stroud, W. Gong, and S. Gong, as well as S. Gravel. They thank P. Cheung, K. Wong and T. Mahtani for their assistance in generating some of the figures herein. They also thank Nathalie Mayrand (Rio Tinto Alcan) and the California Air Resources Board for sharing measurement data from the Kitimat area and California, respectively. Finally, the authors thank T. Bidleman and M. Diamond for their guidance and support at the outset of this project.

Edited by: J. W. Bottenheim

\section{References}

Aulinger, A., Matthias, V., and Quante, M.: Introducing a partitioning mechanism for PAHs into the Community Multiscale Air Quality modeling system and its application to simulating the transport of benzo[a]pyrene over Europe, J. Appl. Meterol. Clim., 46, 1718-1730, 2007.

Bamford, H. A., Poster, D. L., and Baker, J. E.: Temperature dependence of Henry's Law constants of thirteen polycyclic aromatic hydrocarbons between $4{ }^{\circ} \mathrm{C}$ and $31^{\circ} \mathrm{C}$, Environ. Toxicol. Chem., 18, 1905-1912, 1999.

Behymer, T. D. and Hites, R. A.: Photolysis of polycyclic aromatic hydrocarbons adsorbed on simulated atmospheric particulates, Environ. Sci. Technol., 19, 1004-1006, 1985.

Bidleman, T. F.: Atmospheric processes: Wet and dry deposition of organic compounds are controlled by their vapor-particle partitioning, Environ. Sci. Technol., 22, 361-367, 1988.

Bieser, J., Aulinger, A., Matthias, V., and Quante, M.: Impact of emission reductions between 1980 and 2020 on atmospheric benzo[a]pyrene concentrations over Europe, Water Air Soil Poll., 223, 1393-1414, 2012.

Blanchard, P., Audette, C. V., Hulting, M. L., Basu, I., Brice, K. A., Backus, S. M., Dryfhout-Clark, H., Froude, F., Hites, R. A., Neilson, M., and Wu, R.: Atmospheric deposition of toxic substances to the Great Lakes: IADN results through 2005, ISBN En56-146/2005E, Environment Canada and US EPA, Toronto, 2008.

Bozlaker, A., Muezzinoglu, A., and Odabasi, M.: Atmospheric concentrations, dry deposition and air-soil exchange of polycyclic aromatic hydrocarbons (PAHs) in an industrial region in Turkey, J. Hazard. Mater., 153, 1093-1102, 2008. 
Côté, J., Desmarais, J.-G., Gravel, S., Méthot, A., Patoine, A., Roch, M., and Staniforth, A.: The operational CMC-MRB Global Environment Multiscale (GEM) model: Part I. Design considerations and formulation, Mon. Weather Rev., 126, 1373-1395, 1998a.

Côté, J., Desmarais, J.-G., Gravel, S., Méthot, A., Patoine, A., Roch, M., and Staniforth, A.: The operational CMC-MRB Global Environment Multiscale (GEM) model: Part II. Results, Mon. Weather Rev., 126, 1397-1418, 1998 b.

Dachs, J. and Eisenreich, S. J.: Adsorption onto aerosol soot carbon dominates gas-particle partitioning of polycyclic aromatic hydrocarbons, Environ. Sci. Technol., 34, 3690-3697, 2000.

Diamond, M. L., Gingrich, S. E., Fertuck, K., McCarry, B. E., Stern, G. A., Billeck, B., Grift, B., Brooker, D., and Yager, T. D.: Evidence for organic film on an impervious urban surface: characterization and potential teratogenic effects, Environ. Sci. Technol., 34, 2900-2908, 2000.

District of Kitimat: Kitimat, British Columbia Community Profile, District of Kitimat, B.C., http://www.kitimat.ca/assets/Residents/ PDFs/community-profile.pdf (last access: 25 August 2011), 2009.

Environment Canada and Health Canada: Canadian Environmental Protection Act: Priority Substances List Assessment Report: Polycyclic Aromatic Hydrocarbons, Government of Canada, Ottawa, ON, Cat. No. En40-215/42E, 66 pp., 1994.

Environment Canada: Historical emission trends for benzo[a]pyrene in Canada (kilograms), http://www.ec. gc.ca/pdb/websol/emissions/ap/ap_result_e.cfm?year= 1985-2007\&substance=bap $\&=$ CA\&sector $=\&$ submit $=$ Search (last access: 28 September 2012), 2012.

Esteve, W., Budzinski, H., and Villenave, E.: Relative rate constants for the heterogeneous reactions of $\mathrm{NO}_{2}$ and $\mathrm{OH}$ radicals with polycyclic aromatic hydrocarbons adsorbed on carbonaceous particles. Part 2: PAHs adsorbed on diesel particulate exhaust SRM 1650a, Atmos. Environ., 40, 201-211, 2006.

Finizio, A., Mackay, D., Bidleman, T., and Harner, T.: Octanol-air partition coefficient as a predictor of partitioning of semi-volatile organic chemicals to aerosols, Atmos. Environ., 31, 2289-2296, 1997.

Friedman, C. L. and Selin, N. E.: Long-range atmospheric transport of polycyclic aromatic hydrocarbons: a global 3-D model analysis including evaluation of arctic sources, Environ. Sci. Technol, 46, 9501-9510, 2012.

Galarneau, E.: Source specificity and atmospheric processing of airborne PAHs: implications for source apportionment, Atmos. Environ., 42, 8139-8149, 2008.

Galarneau, E. and Dann, T.: Air toxics in Canada (ATiC): preliminary scoping report, Environment Canada, Toronto, ON, 24 pp., 2011.

Galarneau, E., Bidleman, T. F., and Blanchard, P.: Seasonality and interspecies differences in particle/gas partitioning of PAHs observed by the Integrated Atmospheric Deposition Network (IADN), Atmos. Environ, 40, 182-197, 2006.

Galarneau, E., Makar, P. A., Sassi, M., and Diamond, M. L.: Estimation of atmospheric emissions of six semivolatile polycyclic aromatic hydrocarbons in southern Canada and the United States by use of an emissions processing system, Environ. Sci. Technol., 41, 4205-4213, 2007.

Galarneau, E.: Evaluation of particle/gas partitioning in a regional air quality model (AURAMS-PAH), in preparation, 2014.
Gong, S. L., Barrie, L. A., Blanchet, J.-P., von Salzen, K., Lohmann, U., Lesins, G., Spacek, L., Zhang, L. M., Girard, E., Lin, H., Leaitch, R., Leighton, H., Chylek, P., and Huang, P.: Canadian Aerosol Module: A size-segregated simulation of atmospheric aerosol processes for climate and air quality models. 1. Module development, J. Geophys. Res., 108, 4007, doi:10.1029/2001JD002002, 2003a.

Gong, S. L., Barrie, L. A., and Lazare, M.: Canadian Aerosol Module (CAM): A size-segregated simulation of atmospheric aerosol processes for climate and air quality models 2. Global sea-salt aerosol and its budgets, J. Geophys. Res., 107, 4779, doi:10.1029/2001JD002004, 2003b.

Gong, W., Dastoor, A. P., Bouchet, V. S., Gong, S., Makar, P. A., Moran, M. D., Pabla, B., Ménard, S., Crevier, L.-P., Cousineau, S., and Venkatesh, S.: Cloud processing of gases and aerosols in a regional air quality model (AURAMS), Atmos. Res., 82, 248275, 2006.

Gusev, A., Dutchak, S., Rozovskaya, O., Shatalov, V., Sokovykh, V., Vulykh, N., Aas, W., and Breivik, K.: Persistent organic pollutants in the environment, EMEP Status Report 3/2011, NILU and MSC-East, 2011.

Hafner, W. D., Carlson, D. L., and Hites, R. A.: Influence of local human population on atmospheric polycyclic aromatic hydrocarbon concentrations, Environ. Sci. Technol., 39, 7374-7379, 2005.

Halsall, C. J., Sweetman, A. J., Barrie, L. A., and Jones, K. C.: Modelling the behaviour of PAHs during atmospheric transport from the UK to the Arctic, Atmos. Environ., 35, 255-267, 2001.

Hoff, R. M.. Strachan, W. M. J., Sweet, C. W., Chan, C. H., Shackleton, M., Bidleman, T. F., Brice, K. A., Burniston, D. A., Cussion, S., Gatz, D. F., Harlin, K., and Schroeder, W. H.: Atmospheric deposition of toxic chemicals to the Great Lakes: a review of data through 1994, Atmos. Environ., 30, 3505-3527, 1996.

Hung, H., Blanchard, P., Halsall, C. J., Bidleman, T. F., Stern, G. A., Felin, P., Muir, D. C. G, Barrie, L. A., Jantunen, L. M., Helm, P. A., Ma, J., and Konoplev, A.: Temporal and spatial variabilities in atmospheric polychlorinated biphenyls (PCBs), organochlorine (OC) pesticides and polycyclic aromatic hydrocarbons (PAHs) in the Canadian Arctic: results from a decade of monitoring, Sci. Total. Environ., 342, 119-144, 2005.

Inomata, Y., Kajino, M., Sato, K., Ohara, T., Kurokawa, J.-I., Ueda, H., Tang, N., Hayakawa, K., Ohizumi, T., and Akimoto, H.: Emission and atmospheric transport of particulate PAHs in Northeast Asia, Environ. Sci. Technol., 46, 4941-4949, 2012.

International Agency for Research on Cancer: IARC Monographs on the Evaluation of Carcinogenic Risks to Humans: VOLUME 92: Some Non-heterocyclic Polycyclic Aromatic Hydrocarbons and Some Related Exposures, IARC, Lyon, France, 2010.

Jonker, M. T. O. and Koelmans, A. A.: Sorption of polycyclic aromatic hydrocarbons and polychlorinated bipheyls to soot and soot-like materials in the aqueous environment: mechanistic considerations, Environ. Sci. Technol., 36, 3725-3734, 2002.

Jones, K. C.: Observations on long-term air-soil exchange of organic contaminants, Environ. Sci. Pollut. R., 1, 172-177, 1994.

Junge, C. E.: Basic considerations about trace constituents in the atmosphere as related to the fate of global pollutants, in: Fate of Pollutants in the Air and Water Environments, edited by: Suffet, I. H., Wiley, New York, 7-25, 1977. 
Kelly, F. J. and Fussell, J.: Review: Size, source and chemical composition as determinants of toxicity attibutable to ambient particulate matter, Atmos. Environ., 60, 504-526, 2012.

Kelly, J., Makar, P. A., and Plummer, D. A.: Projections of mid-century summer air-quality for North America: effects of changes in climate and precursor emissions, Atmos. Chem. Phys., 12, 5367-5390, doi:10.5194/acp-12-5367-2012, 2012.

Kwamena, N.-O. A., Thornton, J. A., and Abbatt, J. P. D.: Kinetics of surface-bound benzo[a]pyrene and ozone on solid organic and salt aerosols, J. Phys. Chem. A, 108, 11626-11634, 2004.

Lammel, G., Sehili, A. M., Bond, T. C., Feichter, J., and Grassl, H.: Gas/particle partitioning and global distribution of polycyclic aromatic hydrocarbons: a modelling approach, Chemosphere, 76, 98-106, 2009.

Lang, C., Tao, S., Zhang, G., Fu, J., and Simonich, S.: Outflow of polycyclic aromatic hydrocarbons from Guangdong, southern China, Environ. Sci. Technol., 41, 8370-8375, 2007.

Lang, C., Tao, S., Liu, W., Zhang, Y., and Simonich, S.: Atmospheric transport and outflow of polycyclic aromatic hydrocarbons from China, Environ. Sci. Technol., 42, 5196-5201, 2008.

Liu, S., Tao, S., Liu, W., Liu, Y., Dou, H., Zhao, J., Wang, L., Wang, J., Tian, Z., and Gao, Y.: Atmospheric polycyclic aromatic hydrocarbons in north China: a winter-time study, Environ. Sci. Technol., 41, 8256-8261, 2007.

Mackay, D., Shiu, W. Y., Ma, K.-C., and Lee, S. C: Handbook of physical-chemical properties and environmental fate for organic chemicals. Vol. 1: Introduction and hydrocarbons. Taylor and Francis, Boca Raton, FL, USA, 2006.

Makar, P. A., Zhang, J., Gong, W., Stroud, C., Sills, D., Hayden, K. L., Brook, J., Levy, I., Mihele, C., Moran, M. D., Tarasick, D. W., He, H., and Plummer, D.: Mass tracking for chemical analysis: the causes of ozone formation in southern Ontario during BAQS-Met 2007, Atmos. Chem. Phys., 10, 11151-11173, doi:10.5194/acp-10-11151-2010, 2010.

Matthias, V., Aulinger, A., and Quante, M.: CMAQ simulations of the benzo[a]pyrene distribution over Europe for 200 and 2001, Atmos. Environ., 43, 4078-4086, 2009.

McDow, S. R.: Sampling artefact errors in gas/particle partitioning measurements, in: Gas and Particle Phase Measurements of Atmospheric Organic Compounds, edited by: Lane, D. A., Gordon and Breach Science Publishers, Canada, 105-126, 1999.

McKeen, S., Chung, S. H., Wilczak, J., Grell, G., Djalalova, I., Peckham, S., Gong, W., Bouchet, V., Moffet, R., Tang, Y., Carmichael, G. R., Mathur, R., and Yu, S.: Evaluation of several real-time $\mathrm{PM}_{2.5}$ forecast models using data collected during the ICARTT/NEAQS 2004 field study, J. Geophys. Res., 112, D10S20, doi:10.1029/2006JD007608, 2007.

Menichini, E.: On-filter degradation of particle-bound benzo[a]pyrene by ozone during air sampling: a review of the experimental evidence of an artefact, Chemosphere, 77, 1275-1284, 2009.

Motelay-Massei, A., Harner, T., Shoeib, M., Diamond, M., Stern, G., and Rosenberg, B.: Using Passive Air Samplers To Assess Urban-Rural Trends for Persistent Organic Pollutants and Polycyclic Aromatic Hydrocarbons. 2. Seasonal Trends for PAHs, PCBs, and Organochlorine Pesticides, Environ. Sci. Technol., 39, 5763-5773, 2005.

Nelson, E. D., McConnell, L. L., and Baker, J. E.: Diffusive exchange of gaseous polycyclic aromatic hydrocarbons and poly- chlorinated biphenyls across the air-water interface of the Chesapeake Bay, Environ. Sci. Technol., 32, 912-919, 1998.

Odabasi, M., Cetin, E., and Sofuoglu, A.: Determination of octanoair partition coefficients and supercooled liquid vapour pressures of PAHs as a function of temperature: application to gas-particle partitioning in an urban atmosphere, Atmos. Environ., 40, 6615$6625,2006$.

Offenberg, J. H. and Baker, J. E.: Aerosol size distributions of polycylic aromatic hydrocarbons in urban and over-water atmospheres, Environ. Sci. Technol., 33, 3324-3331, 1999.

Pankow, J. F.: Review and comparative analysis of the theories on partitioning between the gas and aerosol particulate phases in the atmosphere, Atmos. Environ., 21, 2275-2283, 1987.

Pöschl, U., Letzel, T., Schauer, C., and Niessner, R.: Interaction of ozone and water vapor with spark discharge soot aerosol particles coated with benzo[a]pyrene: $\mathrm{O}_{3}$ and $\mathrm{H}_{2} \mathrm{O}$ adsorption, benzo[a]pyrene degradation, and atmospheric implications, J. Phys. Chem. A, 105, 4029-4041, 2001.

Prevedouros, K., Jones, K. C., and Sweetman, A. J.: Modelling the atmospheric fate and seasonality of polycyclic aromatic hydrocarbons in the UK, Chemosphere, 56, 195-208, 2004.

Prevedouros, K., Palm-Cousins, A., Gustafsson, Ö., and Cousins, I. T.: Development of a black carbon-inclusive multi-media model: application for PAHs in Stockholm, Chemosphere, 70, 607-615, 2008.

Reid, R. C., Prausnitz, J. M., and Poling, B. E.: The properties of gases and liquids, McGraw-Hill, Toronto, 1987.

Sehili, A. M. and Lammel, G.: Global fate and distribution of polycyclic aromatic hydrocarbons emitted from Europe and Russia, Atmos. Environ., 41, 8301-8315, 2007.

Shatalov, V., Gusev, A., Dutchak, S., Holoubek, I., Mantseva, E., Tozovskaya, O., Sweetman, A., Strukov, B., and Vulykh, N.: Modelling of POP contamination in European region: evaluation of the model performance, EMEP/MSC-E Technical Report 7/2005, 2005.

Shiraiwa, M., Garland, R. M., and Pöschl, U.: Kinetic double-layer model of aerosol surface chemistry and gas-particle interactions (K2-SURF): Degradation of polycyclic aromatic hydrocarbons exposed to $\mathrm{O}_{3}, \mathrm{NO}_{2}, \mathrm{H}_{2} \mathrm{O}, \mathrm{OH}$ and $\mathrm{NO}_{3}$, Atmos. Chem. Phys., 9, 9571-9586, doi:10.5194/acp-9-9571-2009, 2009.

Smith, K. E. C, Thomas, G. A., and Jones, K. C.: Seasonal and species differences in the air-pasture transfer of PAHs, Environ. Sci. Technol., 35, 2156-2165, 2001.

Smyth, S. C., Jiang, W., Roth, H., Moran, M. D., Makar, P. A., Yang, F., Bouchet, V. S., and Landry, H.: A comparative performance evaluation of the AURAMS and CMAQ air-quality modelling systems, Atmos. Environ., 43, 1059-1070, 2009.

Solazzo, E., Bianconi, R., Vautard, R., Appel, K. W., Moran, M. D., Hogrefe, C., Bessagnet, B., Brandt, J., Christensen, J. H., Chemel, C., Coll, I., Denier van der Gon, H., Ferreira, J., Forkel, R., Francis, X. V., Grell, G., Grossi, P., Hansen, A. B., Jeričević, A., Kraljević, L., Miranda, A. I., Nopmongcol, U., Pirovano, G., Prank, M., Riccio, A., Sartelet, K. N., Schaap, M., Silver, J. D., Sokhi, R. S., Vira, J., Werhahn, J., Wolke, R., Yarwood, G., Zhang, J., Rao, S. T., and Galmarini, S.: Model evaluation and ensemble modelling of surface-level ozone in Europe and North America in the context of AQMEII. Atmos. Environ., 53, 60-74, 2012. 
Statistics Canada: Population of census metropolitan areas, available at: http://www40.statcan.ca/101/cst01/demo05a-eng. htm (last access: 25 August 2011), 2011.

Stroud, C. A., Makar, P. A., Moran, M. D., Gong, W., Gong, S., Zhang, J., Hayden, K., Mihele, C., Brook, J. R., Abbatt, J. P. D., and Slowik, J. G.: Impact of model grid spacing on regionaland urban- scale air quality predictions of organic aerosol, Atmos. Chem. Phys., 11, 3107-3118, doi:10.5194/acp-11-31072011, 2011.

US EPA: Estimation program interface (EPI) suite, available at: http://www.epa.gov/opptintr/exposure/pubs/episuite.htm (last access: 2 June 2006), 2006

US EPA: The Clean Air Act Amendments of 1990 List of Hazardous Air Pollutants, available at: http://www.epa.gov/ttnatw01/ orig189.html, (last access: 28 September 2012), 2012a.

US EPA: National-scale air toxics assessment (NATA). Summary of results for the 2005 national-scale assessment, http://www. epa.gov/ttn/atw/nata2005/05pdf/sum_results.pdf (last access: 28 September 2012), 2012b.

US EPA: TRI Explorer Web Tool, available at: http://iaspub.epa. gov/triexplorer/tri_release.chemical, (last access: 28 September 2012), 2012c.

Van Jaarsveld, J. A., Van Pul, W. A. J., and De Leeuw, F. A. A. M.: Modelling transport and deposition of persistent organic pollutants in the European region, Atmos. Environ., 31, 1011-1024, 1997.
Wang, W., Simonich, S., Giri, B., Chang, Y., Zhang, Y., Jia, Y., Tao, S., Wang, R., Wang, B., Li, W., Cao, J., and Lu, X.: Atmospheric concentrations and air-soil gas exchange of polycyclic aromatic hydrocarbons (PAHs) in remote, rural village and urban areas of Beijing-Tianjin region, North China, Sci. Total. Environ., 409, 2942-2950, 2011.

Yaffe, D., Cohen, Y., Arey, J., and Grosovsky, A. J.: Multimedia analysis of PAHs and nitro-PAH daughter products in the Los Angeles Basin, Risk Anal., 21, 275-294, 2001.

Zhang, L., Moran, M. D., Makar, P. A., Brook, J. R., and Gong, S.: Modelling gaseous dry deposition in AURAMS: an unified regional air-quality modelling system, Atmos. Environ., 36, 537560, 2002.

Zhang, Y., Tao, S., Shen, H., and Ma, J.: Inhalation exposure to ambient polycyclic aromatic hydrocarbons and lung cancer risk of Chinese population, P. Natl. Acad. Sci. USA, 106, 21063-21067, 2009.

Zhang, Y., Shen, H., Tao, S., and Ma, J.: Modeling the atmospheric transport and outflow of polycyclic aromatic hydrocarbons emitted from China, Atmos. Environ., 45, 2820-2827, 2011a.

Zhang, Y., Tao, S., Ma, J., and Simonich, S.: Transpacific transport of benzo[a]pyrene emitted from Asia, Atmos. Chem. Phys., 11, 11993-12006, doi:10.5194/acp-11-11993-2011, 2011 b. 